\title{
ANALISIS KERAWANAN BANJIR MENGGUNAKAN PENDEKATAN GEOMORFOLOGI DI DKI JAKARTA
}

\section{FLOOD SUSCEPTIBILITY ANALYSIS USING GEOMORPHOLOGY APPROACH IN THE SPECIAL CAPITAL REGION OF JAKARTA}

\author{
Siti Dahlia, Tricahyono, NH, dan Wira Fazri Rosyidin \\ Dosen Pendidikan Geografi FKIP UHAMKA e-mail: dahliasiti51@yahoo.com
}

\begin{abstract}
Special Capital Region of Jakarta Province is Capital City of Indonesia, which has various strategic functions, such as central government and economic and business center. Geographically DKI Jakarta Province is lowland, it caused Jakarta has high of flood hazard. This condition potentially result of high risk. Based on it, the aims of research is: 1). Making map of flood susceptibility in Special Capital Region of Jakarta area, based on geomorphology approach, and 2). Data inventory element at risk of flood. The method of data analysis used qualitative, based on interpretation satellite imagery data using elements of interpretation. Indicators used to result map of flood susceptibility are elevation, slope, and landform, using scoring and overlay technique. The result of research is flood susceptibility of low area is 13.613,40 ha, medium is 23.238,67 ha, and higt is 27.216,72 ha. Based on it, the majority of research area have hight of flood susceptibility. Based on spatial pattern, it showed that areas with high flood susceptibility are mostly located in the northern part of research area, and areas with the lowest flood susceptibility are majority in the southern part of researh area. The result analysis of element at risk, it showed that element at risk affected by flood for high, medium, or low level is settlement.
\end{abstract}

\section{Keywords: Flood Susceptibility of Map, Exposure, Geomorphology, and Special Capital} Region of Jakarta

\begin{abstract}
ABSTRAK
Provinsi DKI Jakarta merupakan Ibu Kota negara Indonesia yang memiliki beragam fungsi startegis, seperti pusat pemerintahan, dan pusat ekonomi dan bisnis. Akan tetapi, kondisi geografis Provinsi DKI Jakarta yang merupakan dataran rendah, mengakibatkan wilayah Jakarta memiliki ancaman tinggi terhadap bahaya banjir. Hal ini dapat berpotensi menghasilkan tingginya risiko kerugian terhadap bencana. Berdasarkan hal tersebut, tujuan dalam penelitian ini yaitu: 1) Membuat peta kerawanan banjir Provinsi DKI Jakarta berdasarkan pendekatan geomorfologi, dan 2). Melakukan inventarisasi elemen berisiko yang berpotensi terpapar banjir. Metode analisis data dalam penelitian ini menggunakan analisis kualitatif, karena berdasarkan teknik interpretasi data citra secara kualitatif yaitu menggunakan unsur-unsur interpretasi. Parameter-parameter yang digunakan untuk menghasilkan peta kerawanan banjir yaitu elevasi, kemiringan lereng, dan bentuk lahan, dengan menggunakan skoring dan tumpang susun. Hasil penelitian menunjukkan bahwa tingkat kerawanan banjir rendah seluas $13.613,40$ ha, sedang seluas 23.238,67 ha, dan tinggi seluas $27.216,72$ ha. Mayoritas wilayah penelitian terletak pada tingkat kerawanan banjir tinggi. Berdasarkan pola spasial menunjukkan bahwa daerah dengan tingkat kerawanan banjir tinggi mayoritas terletak di bagian utara wilayah penelitian, dan daerah dengan tingkat kerawanan banjir rendah mayoritas dibagian selatan wilayah penelitian. Hasil analisis keterpaparan elemen berisiko wilayah penelitian menunjukkan bahwa elemen berisiko yang berpotensi tertinggi terkena banjir baik tingkat tinggi, sedang, atau rendah yaitu pemukiman.
\end{abstract}

Katakunci: Pemetaan Kerawanan Banjir, Keterpaparan, Gemorfologi, dan DKI Jakarta

\section{PENDAHULUAN}

Provinsi DKI Jakarta merupakan lbu Kota negara Indonesia yang memiliki beragam fungsi startegis, seperti pusat pemerintahan, dan pusat ekonomi dan bisnis. Berdasarkan informasi portal DKI Jakarta pendapatan daerah Provinsi DKI Jakarta yaitu Rp. 60,4 Trilyun Rupiah, dengan 
luas wilayah yaitu $661,52 \mathrm{~km}^{2}$. Data menurut BPBD (2017), Provinsi DKI Jakarta merupakan salah satu provinsi di Indonesia yang memiliki kerawanan terhadap multi bencana, seperti banjir, longsor, penurunan daratan, cuaca ekstrem, bencana non alam, dan lain-lain. Kondisi tersebut dapat diidentifikasi salah satunya disebabkan oleh $40 \%$ wilayah DKI Jakarta merupakan terletak di dataran rendah, dengan ketinggian rata-rata dibawah permukaan air laut.

Secara geomorfologi mayoritas wilayah Jakarta merupakan bentukan hasil proses fluvial, dan terletak di bagian Utara Pulau Jawa. Kondisi tersebut mengakibatkan daerah DKI Jakarta rawan terhadap bahaya hidro meteorologis khususnya banjir. Menurut BPBD Jakarta (2017), kerugian akibat banjir Jabodetabek tahun 2007, mencapai Rp. 5,16 trilyun.

Berdasarkan kondisi tersebut menunjukkan bahwa Provinsi DKI Jakarta sebagai wilayah yang memiliki fungsi strategis di negara, memiliki ancaman tinggi terhadap bahaya banjir. Hal ini dapat berpotensi menghasilkan tingginya risiko kerugian terhadap bencana. Berdasarkan kondisi tersebut untuk itu penting untuk melakukan zonasi terkait daerah rawan banjir dan inventarisasi elemen berisiko di wilayah DKI Jakarta, sebagai bentuk salah satu upaya mitigasi bencana untuk penurunan tingkat risiko.

Pemetaan daerah rawan banjir merupakan tahapan penting sebelum melakukan perencanaan kontrol terhadap banjir (Sinha et al., 2008). Pada analisis risiko pemetaan daerah rawan banjir merupakan tahapan awal dalam pemetaan risiko (Andrade dan Szlafsztein, 2015). Selain itu, pemetaan daerah rawan banjir dan diserta perencanaan penggunaan lahan dapat menurunkan efek dari suatu bencana (Furdada et al., 2008).

Penelitian terkait banjir terus berkembang dengan berbagai metode dan pendekatan, mengingat pada saat ini kajian bencana menjadi salah satu fokus kajian penting khususnya di Indonesia yang merupakan negara rawan terhadap bencana banjir. Selain itu, kondisi ini disebabkan oleh risiko banjir bagi masyarakat dataran rendah diperkirakan akan meningkat di masa depan di berbagai bagian dunia, hal ini disebabkan oleh berbagai faktor pemicu termasuk perubahan iklim (curah hujan

meningkat, limpasan ekstrem, naiknya permukaan air laut), penurunan tanah, perubahan penggunaan lahan, pertumbuhan populasi, dan peningkatan aset yang berada di daerah rawan banjir (Marfai et al., 2014).

Pendekatan yang dapat digunakan untuk penilaian atau pemetaan bahaya banjir yaitu pendekatan hidrologi, geomorfologi, penginderaan jauh, Software, statistik, dan participatory GIS (Lastra J, 2008; van Westen et al., 2011; Dao dan Liou, 2015). Pada penelitian ini dalam mengkaji daerah rawan banjir DKI Jakarta menggunakan pendekatan geomorfologi.

Identifikasi daerah rawan banjir dapat menggunakan pendekatan geomorfologi, karena karakteristik geomorfologi menjadi kunci dalam kajian potensi banjir, banjir genangan ataupun jejak-jejaknya dapat dikenali dari pola bentuk lahan pada dataran rendah (Setiawan et al., 2014). Selain itu, Satuan bentuk lahan dan persepsi masyarakat dapat digunakan untuk identifikasi karaktersitik dan pemetaan daerah rawan banjir (Dahlia et al., 2016)

Berdasarkan hal tersebut penelitian ini memiliki tujuan: (1) Membuat peta kerawanan banjir Provinsi DKI Jakarta berdasarkan pendekatan geomorfologi, dan (2). Melakukan inventarisasi elemen berisiko yang berpotensi terpapar banjir. Pertanyaan penelitian yang dibangun dalam penelitian ini yaitu: (1). Bagaimana distribusi spasial tingkat kerawanan

banjir wilayah penelitian, berdasarkan pendekatan geomorfologi. (2). Elemen berisiko apa sajakah yang berpotensi terpapar banjir?

\section{METODE PENELITIAN}

\subsection{Waktu dan Tempat Penelitian}

Penelitian ini dilakukan di wilayah Provinsi DKI Jakarta yang meliputi Jakarta Timur, Jakarta Barat, Jakarta Utara, Jakarta Selatan, dan Jakarta Pusat, dengan luas $661,52 \mathrm{~km}^{2}$. Secara astronomis wilayah penelitian terletak diantara 106 22'42"'-106 58'188" 6 22' " $6222^{\prime} 45 \quad G \quad 1$ 1). Secara morfologi wilayah penelitian merupakan dataran rendah, sehingga setiap tahun terkena banjir khususnya pada musim penghujan. Waktu penelitian dilaksanakan pada Bulan April sampai Juni Tahun 2017. 


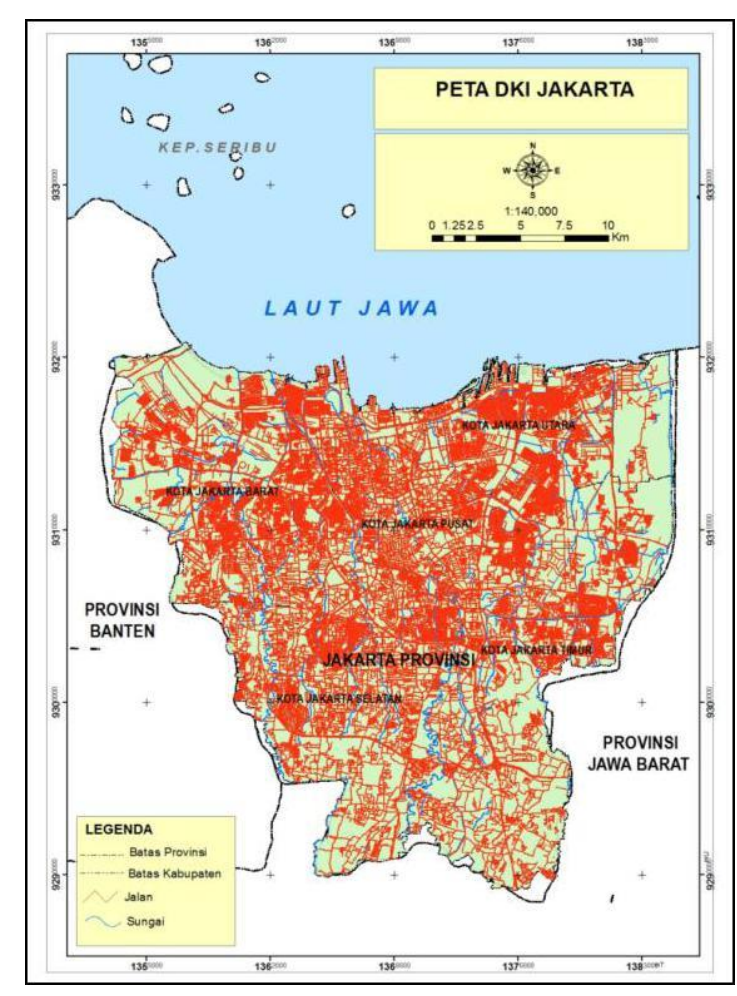

Gambar 1. Lokasi Penelitian

\subsection{Bahan dan Data}

Bahan dan data yang digunakan dalam penelitian disajikan pada Tabel 1.

Tabel 1. Bahan dan Data Penelitian

\begin{tabular}{|c|c|c|}
\hline No & Bahan dan Data & Sumber \\
\hline 1 & $\begin{array}{c}\text { Peta RBI skala } \\
1: 25.000\end{array}$ & BAKOSURTANAL \\
\hline 2 & Citra Landsat 8 & USGS \\
\hline 3 & $\begin{array}{c}\text { Citra DEM SRTM } \\
\text { Resolusi 30 m }\end{array}$ & USGS \\
\hline 4 & Data Historis Banjir & Survei Lapangan \\
\hline
\end{tabular}

\subsection{Analisis Data}

Metode analisis data dalam penelitian ini menggunakan analisis kualitatif, karena berdasarkan teknik interpretasi data citra secara kualitatif yaitu menggunakan unsur-unsur interpretasi seperti pola, tekstur, asosiasi, rona, bentuk, dan lain-lain. Parameter- parameter yang digunakan untuk menghasilkan peta kerawanan banjir yaitu elevasi, kemiringan lereng, dan bentuklahan.

Pengolahan data dalam penelitian ini untuk menghasilkan parameter-parameter tersebut yaitu terdiri dari pengolahan data sekunder dan primer hasil pengumpulan data lapangan. Teknik pengolahan data sekunder yaitu untuk data Peta RBI, Citra Landast 8, dan Citra DEM SRTM menggunakan softwareArc Gis 10.3, dengan teknik interpretasi citra untuk menghasilkan Peta Administratif, peta elevasi, Peta Lereng, Peta Bentuklahan, dan peta penggunaan lahan.

Metode analisis data setiap parameter untuk membentuk peta kerawanan banjir menggunakan teknik skoring, skor yang digunakan untuk setiap parameter disajikan pada Tabel 2. Hasil peta kerawanan banjir dari pengolahan data sekunder dilakukan validasi dengan cara survei lapangan, dan wawancara kepada masyarakat setempat terkait kejadian banjir yang pernah terjadi.

Peta kerawanan banjir yang sudah divalidasi dilakukan tumpang susun dengan peta penggunaan lahan, sehingga menghasilkan peta keterpaparan (exposure).

Tabel 2. Parameter yang Digunakan untuk Analisis Kerawanan Banjir

\begin{tabular}{|c|c|c|c|}
\hline No & Parameter & Interval & Skor \\
\hline 1 & Elevasi & $<5 \mathrm{~m}$ & 3 \\
\hline & & $5-50 \mathrm{~m}$ & 2 \\
\hline & & $>50 \mathrm{~m}$ & 1 \\
\hline 2 & $\begin{array}{c}\text { Kemiringan } \\
\text { Lereng }\end{array}$ & $0-2 \%$ & 3 \\
\hline & & $3-7 \%$ & 2 \\
\hline & & $8-13 \%$ & 1 \\
\hline 3 & Bentuklahan & $\begin{array}{c}\text { Dataran Aluvial } \\
\text { Pantai, Dataran } \\
\text { Banjir }\end{array}$ & 3 \\
\hline & & Dataran Aluvial & 2 \\
\hline & & Kipas Aluvial & 1 \\
\hline
\end{tabular}

Sumber: Andrade dan Szlafsztein, 2015

\section{HASIL DAN PEMBAHASAN}

\subsection{Peta Kerawanan Banjir Wilayah Penelitian}

Pemetaan kerawanan banjir wilayah penelitian dalam penelitian ini menggunakan pendekatan geomorfologi, parameter-parameter yang digunakan yaitu elevasi, kemiringan lereng, dan bentuk lahan.

\section{Elevasi}

Hasil analisis menunjukkan bahwa elevasi terendah wilayah penelitian yaitu $-6 \mathrm{~m}$ dpal dan tertinggi $77 \mathrm{~m}$ dpal. Berdasarkan luasan, area yang terletak pada elevasi $<5 \mathrm{~m}$ dpal (rendah) seluas 29132,72 ha, elevasi 5-10 m dpal 
(sedang) seluas 31190,08 ha, dan elevasi $50-$ $77 \mathrm{~m}$ dpal (tinggi) yaitu seluas 3745,88 ha. Berdasarkan hal tersebut, menunjukkan bahwa wilayah penelitian sebagian besar memiliki elevasi 5-10 $\mathrm{m}$ dpal atau kategori sedang (Gambar 2). Menurut van Zuidam (1985), daerah dengan kondisi elevasi $<50 \mathrm{~m}$ merupakan wilayah dataran rendah. Daerah dataran rendah pada umumnya merupakan daerah rawan banjir tahunan, dan merupakan langganan pada beberapa tempat (Sunarto et al., 2014). Kondisi tersebut menunjukkan bahwa secara elevasi wilayah penelitian, rawan terhadap banjir.

Berdasarkan gambar peta elevasi wilayah penelitian (Gambar 2), menunjukkan bahwa elevasi terendah terletak di bagian utara wilayah penelitian, kondisi ini disebabkan oleh bagian utara wilayah penelitian merupakan daerah pesisir, sehingga memiliki elevasi lebih rendah. Elevasi tertinggi wilayah penelitian mayoritas terletak dibagian selatan wilayah penelitian. Kondisi ini disebakan oleh pada bagian selatan

wilayah penelitian merupakan terletak berbatasan dengan wilayah Bogor, yang mayoritas wilayah memiliki karakteristik morfologi berbukit sampai bergunung.

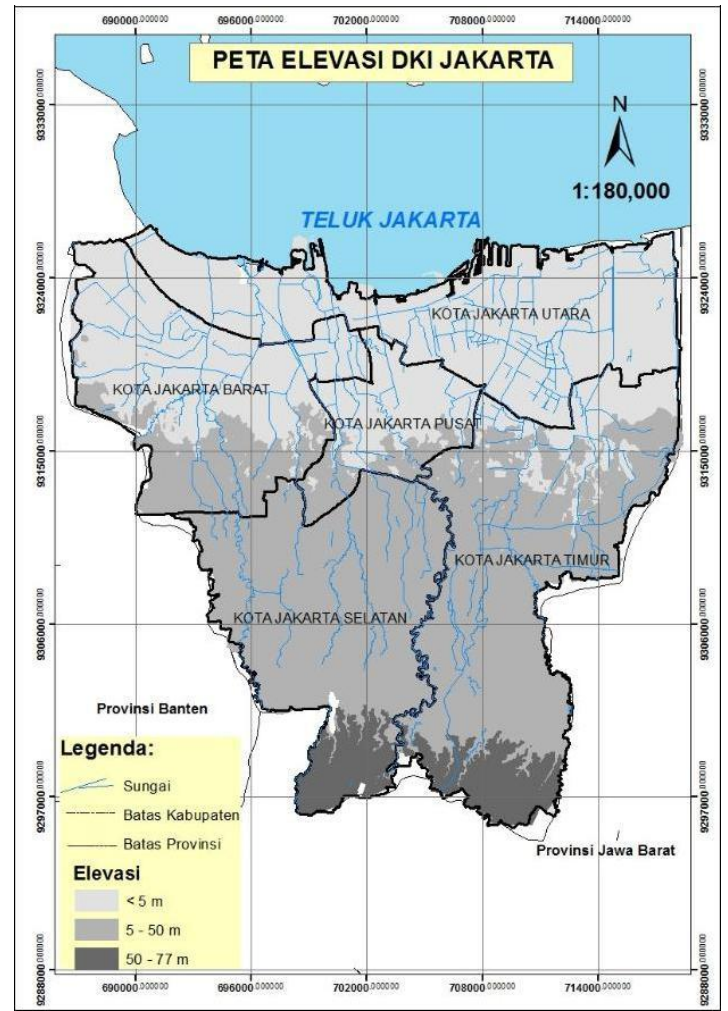

Gambar 2. Peta Elevasi Wilayah Penelitian

\section{Kemiringan Lereng}

Klasifikasi kelas lereng pada penelitian ini mengacu klasifikasi kemiringan lereng menurut van Zuidam Tahun 1985. Hasil analisis menunjukkan bahwa kelas kemiringan lereng DKI Jakarta terdiri dari $0-2 \%$ (datar) seluas 46.592,64 ha, 3-7\% (landai) seluas 13.858,30 ha, dan 8-3 \% (miring) seluas 3617.75 ha. Berdasarkan data luasan tersebut menunjukkan bahwa sebagian besar wilayah penelitian memiliki kemiringan lerengan $0-2 \%$ atau datar. Menurut van Zuidam (1985), daerah dengan kondisi lereng datar sampai landai merupakan daerah dataran banjir. Kondisi tersebut sesuai dengan kondisi di lapangan, bahwa wilayah DKI Jakarta memiliki intensitas tinggi terkena banjir. Peta kemiringan lereng wilayah penelitian disajikan pada Gambar 3

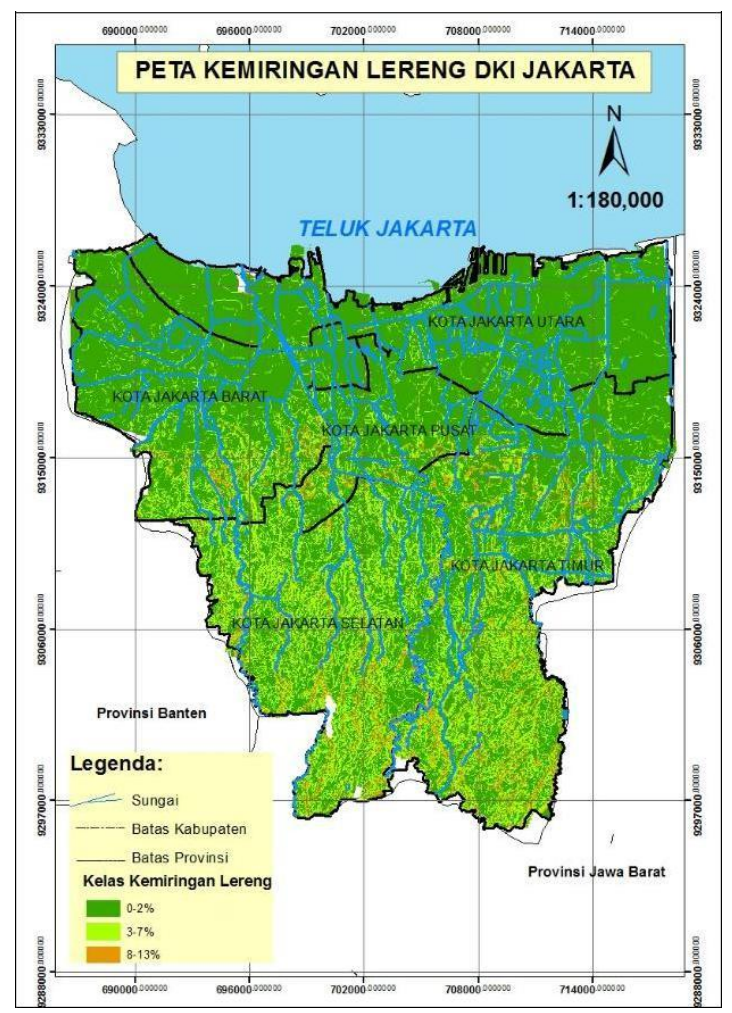

Gambar 3. Peta Kemiringan Lereng

\section{Bentuk lahan}

Daerah rawan banjir dapat diidentifikasi salah satunya yaitu dengan pendekatan geomorfologi. Menurut Setiawan et al (2014), karakteristik geomorfologi menjadi kunci dalam kajian potensi banjir, banjir genangan ataupun jejak-jejaknya dapat dikenali dari pola bentuk lahan pada dataran rendah. Pendekatan bentuk lahan untuk evaluasi bahaya banjir luapan sungai yaitu fokus pada bentuk lahan asal proses fluvial. Bentuk lahan asal proses fluvial 
merupakan bentuk lahan yang terjadi akibat proses air mengalir, baik yang memusat (sungai) maupun oleh aliran permukaan bebas (overland flow). Ketiga aktivitas dari sungai ataupun aliran permukaan bebas tersebut mencakup: erosi, transportasi, dan deposisi atau sedimentasi (Dibyosaputro, 1997).

Hasil analisis peta bentuk lahan, wilayah DKI Jakarta memiliki satuan bentuklahan: dataran alluvial seluas 25.539,07 ha, dataran alluvial pantai seluas 5.996,94 ha, dataran banjir seluas $8.429,12$ ha, dan kipas alluvial seluas 24103.56 ha. Berdasarkan hal tersebut, sebagian besar satuan bentuklahan DKI Jakarta merupakan dataran aluvial (Gambar 4). Dataran alluvial merupakan daerah dengan topografi datar dengan material alluvium yang berasal ketika banjir dan penggenangan. Wilayah Jakarta merupakan muara dari berbagai sungai yang berhulu di wilayah Jawa Barat, kondisi tersebut mengakibatkan wilayah Jakarta didominasi hasil bentukan material alluvium. Selain itu, bentukan terluas di wilayah Jakarta yaitu kipas alluvial merupakan akumulasi sedimen berukuran bongkah, kerakal, kerikil, dan pasir yang terjadi pada suatu daerah yang sungai mengalir, dan terdapat perubahan yang mencolok lereng dari landai hingga miring. Wilayah penelitian memiliki satuan bentuklahan kipas alluvial karena wilayah penelitian berbatasan dengan wilayah Bogor, sehingga wilayah penelitian terpengaruh aliran bahan vulkanis Gunung Gede - Pangrango, dan Gunung Salak (Pannekoek, 1989).

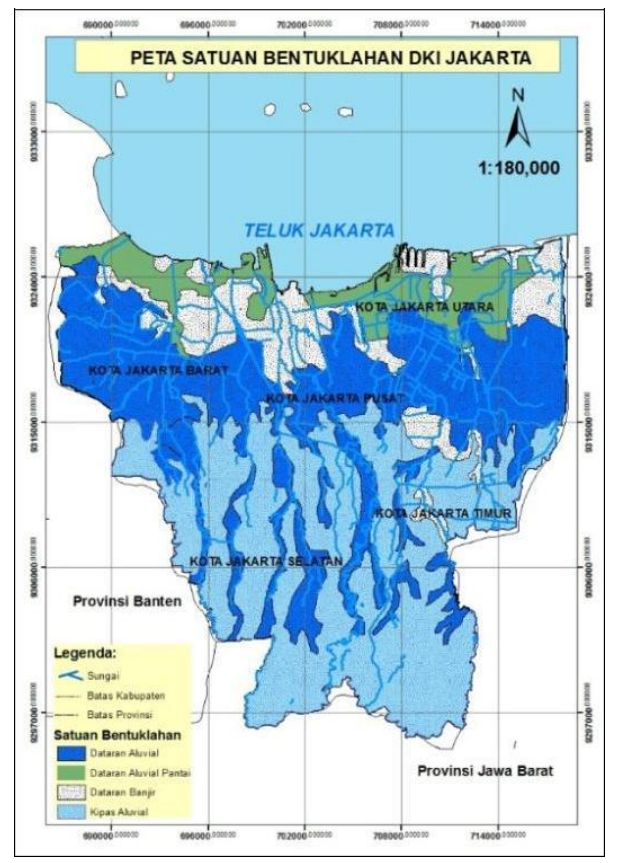

Gambar 4. Peta Bentuk Lahan Wilayah Penelitian

\section{Hasil Peta Kerawanan Banjir Wilayah}

Penelitian

Peta kerawanan banjir wilayah penelitian

dikelaskan menjadi tiga yaitu rendah (hijau), sedang (kuning), dan tinggi (merah) (Gambar 5). Berdasarkan analisis peta kerawanan banjir menunjukkan bahwa daerah dengan tingkat kerawanan banjir rendah seluas $13.613,40$ ha, sedang seluas $23.238,67$ ha, dan tinggi seluas 27.216,72 ha. Berdasarkan data, mayoritas wilayah penelitian terletak pada tingkat kerawanan banjir tinggi. Kondisi ini dapat di identifikasi salah satunya disebabkan oleh faktor wilayah penelitian terletak di pantai Utara Pulau Jawa atau hilir sungai, dan mayoritas daerah dataran rendah.

Berdasarkan peta kerawanan banjir wilayah penelitian (Gambar 5), menunjukkan pola bahwa daerah dengan tingkat kerawanan banjir tinggi mayoritas terletak di bagian utara wilayah penelitian, dan daerah dengan tingkat kerawanan banjir rendah mayoritas dibagian selatan wilayah penelitian. Kondisi tersebut dapat diidentifikasi pengaruh kondisi elevasi, kemiringan lereng, dan bentuk lahan wilayah penelitian. $\mathrm{Hal}$ ini didasarkan atas karakteristik morfologi wilayah DKI Jakarta bagian utara lebih mendukung berpotensi banjir dibandingkan pada wilayah DKI Jakarta bagian selatan.

Pada bagian utara sebagian besar terletak pada elevasi $<5 \mathrm{~m}$ sedangkan pada wilayah selatan 50-77 $\mathrm{m}$. Ditinjau dari kemiringan lereng wilyah bagian utara DKI Jakarta terletak pada kemiringan $0-2 \%$ yaitu datar, sedangkan pada bagian selatan yaitu 8-13\% atau miring. Ditinjau dari bentuk lahan wilyah bagian utara DKI Jakarta mayoritas merupakan bentuk lahan dataran alluvial pantai, dataran aluvial, dan dataran banjir, yang merupakan identitas bentukan - bentukan daerah rawan banjir. Pada wilayah DKI Jakarta bagian selatan terdapat bentukan kipas alluvial dengan kondisi morfologi landau hingga miring, sehingga tidak rawan terhadap banjir. 


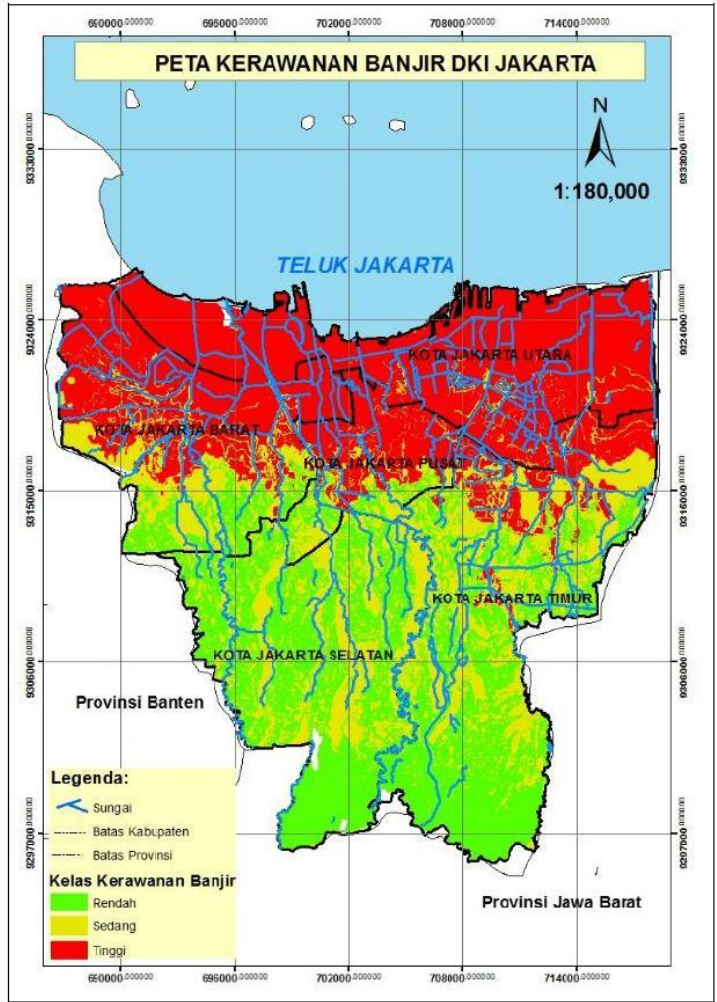

Gambar 5. Peta Kerawanan Banjir Wilayah Penelitian

\subsection{Peta Keterpaparan Banjir Wilayah Penelitian}

Peta keterpaparan elemen berisiko dalam kajian ini, diperoleh dari tumpang susun peta kerawanan banjir dan peta penggunaan lahan wilayah penelitian.

\section{Peta Penggunaan Lahan}

Mayoritas penggunaan lahan DKI Jakarta yaitu untuk pemukiman sebesar $88,37 \%$, kawasan hutan dengan presentase $0,09 \%$, kebun 0,61\%, Padang 0,17\%, Perairan Darat $2,48 \%$, Pertanian Tanah Kering sebesar 3,16\%, dan persawahan $5,07 \%$. Wilayah penelitian mayoritas digunakan sebagai pemukiman karena wilayah penelitian memiliki fungsi sebagai pusat pemerintahan dan ekonomi, sehingga tingginya arus urbanisasi. Kondisi tersebut mengakibatkan rendahnya daerah serapan yang dapat berfungsi sebagai candangan air, sehingga dapat berpengaruh signifikan terhadap kontribusi peningkatan volume banjir karena faktor tingginya air limpasan. Peta penggunaan lahan wilayah DKI Jakarta, disajikan pada Gambar 6 .

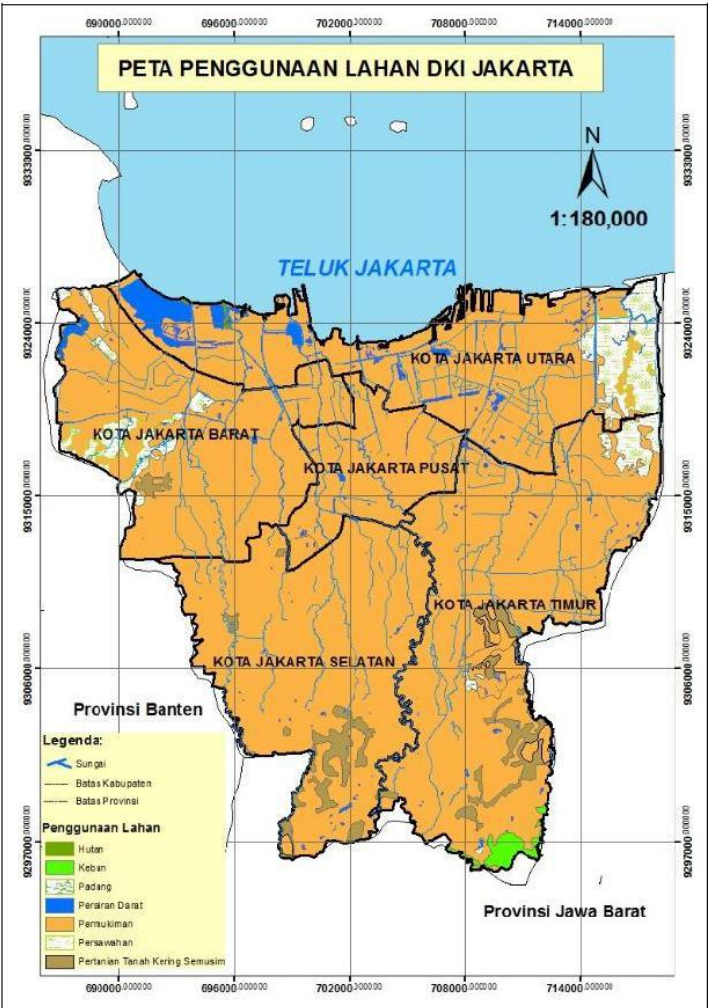

Gambar 6. Peta Penggunaan Lahan

2. Peta Keterpaparan (Eposure)

Keterpaparan (Exposure) merupakan tingkat elemen berisiko yang berpotensi terkena suatu bahaya. Informasi keterpaparan merupakan penting, karena dapat dijadikan sebagai informasi untuk estimasi tingkat risiko, dan dapat dilakukan perencanaan untuk upaya penurunan risiko. Hasil analisis keterpaparan elemen berisiko wilayah penelitian menunjukkan bahwa elemen berisiko yang berpotensi terbanyak terkena banjir baik tingkat tinggi, sedang, atau rendah yaitu pemukiman (Tabel 3.1). Kondisi ini disebabkan oleh faktor mayoritas penggunaan lahan wilayah penelitian merupakan pemukiman, sehingga keterpaparan tertinggi terdapat pada elemen berisiko yaitu pemukiman. 
Tabel 3. Keterpaparan Elemen Berisiko Wilayah Penelitian

\begin{tabular}{|c|c|c|c|}
\hline No & $\begin{array}{c}\text { Kelas } \\
\text { Kerawanan } \\
\text { Baniir }\end{array}$ & $\begin{array}{l}\text { Penggunaan } \\
\text { Lahan }\end{array}$ & $\begin{array}{l}\text { Luas } \\
\text { Terkena } \\
(\mathrm{Ha})\end{array}$ \\
\hline \multirow[t]{8}{*}{1} & Rendah & Hutan & 0 \\
\hline & & Kebun & 355,58 \\
\hline & & Padang & 13,25 \\
\hline & & $\begin{array}{c}\text { Perairan } \\
\text { Darat }\end{array}$ & 100,74 \\
\hline & & Permukiman & $12.149,27$ \\
\hline & & Persawahan & 27,37 \\
\hline & & $\begin{array}{l}\text { Pertanian } \\
\text { Tanah } \\
\text { Kering }\end{array}$ & 967,13 \\
\hline & & Total & $13.613,35$ \\
\hline \multirow[t]{8}{*}{2} & Sedang & Hutan & 0 \\
\hline & & Kebun & 28,08 \\
\hline & & Padang & 42,04 \\
\hline & & $\begin{array}{c}\text { Perairan } \\
\text { Darat }\end{array}$ & 136,89 \\
\hline & & Permukiman & $21.727,43$ \\
\hline & & Persawahan & 372,99 \\
\hline & & $\begin{array}{l}\text { Pertanian } \\
\text { Tanah } \\
\text { Kering }\end{array}$ & 930,63 \\
\hline & & Total & 23238.06 \\
\hline \multirow[t]{8}{*}{3} & Tinggi & Hutan & 1,21 \\
\hline & & Kebun & 0 \\
\hline & & Padang & 55,69 \\
\hline & & $\begin{array}{l}\text { Perairan } \\
\text { Darat }\end{array}$ & $1.320,70$ \\
\hline & & Permukiman & $23.066,73$ \\
\hline & & Persawahan & $2.779,32$ \\
\hline & & $\begin{array}{c}\text { Pertanian } \\
\text { Tanah } \\
\text { Kering }\end{array}$ & 90,38 \\
\hline & & Total & $27.314,04$ \\
\hline
\end{tabular}

Sumber: Analisis data, 2017.

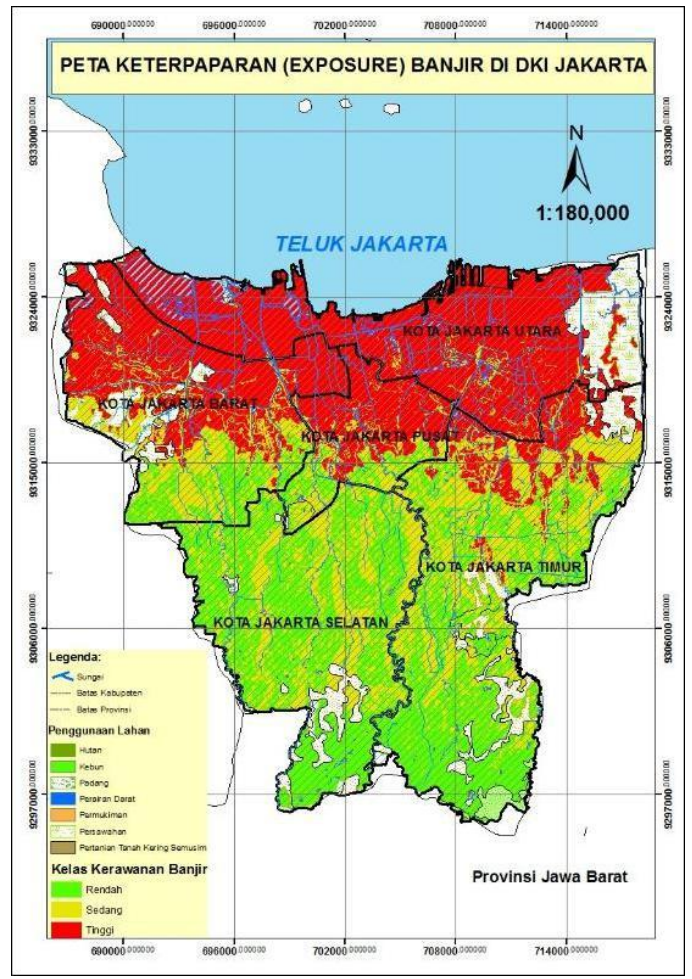

Gambar 7. Peta Keterpaparan Elemen Berisiko Wilayah Penelitian

\section{KESIMPULAN}

Berdasarkan analisis peta kerawanan banjir wilayah penelitian menunjukkan bahwa daerah dengan tingkat kerawanan banjir rendah seluas $13.613,40$ ha, sedang seluas $23.238,67$ ha, dan tinggi seluas $27.216,72$ ha. Hal tersebut menunjukkan bahwa mayoritas wilayah penelitian terletak pada tingkat kerawanan banjir tinggi. Berdasarkan pola spasial menunjukkan bahwa daerah dengan tingkat kerawanan banjir tinggi mayoritas terletak di bagian utara wilayah penelitian, dan daerah dengan tingkat kerawanan banjir rendah mayoritas dibagian selatan wilayah penelitian. Kondisi tersebut dapat diidentifikasi pengaruh elevasi, kemiringan lereng, dan bentuk lahan wilayah penelitian, karena karakteristik morfologi bagian utara wilayah penelitian

mendukung potensi terjadinya banjir dibandingkan bagian selatan.

Hasil analisis keterpaparan elemen berisiko wilayah penelitian menunjukkan bahwa elemen berisiko yang berpotensi terbanyak terkena banjir baik tingkat tinggi, sedang, atau rendah yaitu pemukiman. Kondisi ini disebabkan oleh faktor mayoritas penggunaan lahan wilayah penelitian merupakan pemukiman, sehingga keterpaparan tertinggi terdapat pada elemen berisiko yaitu pemukiman. 


\section{DAFTAR PUSTAKA}

Andrade dan Szlafsztein., 2015, Community Participation in Flood Mapping in the Amazon Through Interdisciplinary Methods, Journal of Natural Hazards, 78:1491-1500.

Dahlia, Siti., Sudibyakto., dan Hizbaron, D.R., 2016. Analisis Risiko Banjir pada Lahan SawahPadi dengan Pendekatan Bentuklahan dan Persepsi Masyarakat di Desa Renged DAS Cidurian, Tesis: Universitas Gadjah Mada.

Dao, P.D dan Liou, Y.-A, 2015, Object-Based Flood Mapping and Affected Rice Field Estimation with Landsat $8 \mathrm{OLI}$ and MODIS Data, Journal of Remote Sensing, 7, 50775097; doi:10.3390/rs70505077.

Dibyosaputro, Suprapto, 1997, Catatan Kuliah Geomorfologi Dasar, Yogyakarta: Fakultas Pascasarjan, Universitas Gadjah Mada.

Furdada, Caldero'n, dan Marque's, 2008, Flood hazard map of La Trinidad, Journal of Natural Hazard 45:183-195.

st J. Fe ' ez E. Di'ez-Herrero, A., dan $M$ qui' ez J 2 8 Flood Hazard Delineation Combining Geomorphological and Hydrological Methods: An Example in The Northern Iberian Peninsula. Journal of Natural Hazards 45:277-293.

Marfai, M.A., Andung, B.S., dan Philip W, 2014, Community Responses and Adaptation Strategies Toward Flood Hazard in Jakarta, Indonesia. Journal of Natural Hazards 75:1127 -1144.

Pannekoek, 1989, Garis Besar Geomorfologi Pulau Jawa.

Setiawan, M.A., H.Warsin., dan Sulistiyaningrum.Y., Potensi Bencana Hidrometeorologi di Kawasan Sub-DAS

Ampel, Kabupaten Jepara, dalam Sunarto., Marfai, M.A., dan Setiawan, M.A., 2014, Geomorfologi dan Dinamika Pesisir Jepara. Gadjah Mada University Press. Yogyakarta

Sinha, R, Bapalu, Singh, dan, Rath. B, 2008, Flood Risk Analysis in the Kosi River Basin, North Bihar using Multi-Parametric Approach of Analytical Hierarchy Process $(A H P)$, Journal of Indian Soc. Remote Sens. 36:335-349.

Sunarto., Rahayu, E., dan Nugrahaeni, L., Deskripsi Lingkungan Wilayah Pesisir Jepara, dalam Sunarto., Marfai, M.A., dan Setiawan, M.A., 2014, Geomorfologi dan Dinamika Pesisir Jepara, Yogyakarta: Gadjah Mada University Press.

Van Westen, C.J., Alkema, D., Damen, MCJ., Kerle, N., dan Kingma, NC, 2011, Multi Hazard Risk Assessment, United Nations
University - ITC School on Disaster

Geoinformation Management.

Van Zuidam, Rober. A, 1985, Aerial Photo Interpretation in Terrain Analysis and Geomorphologic Mapping, Netherlands: Smits Publishers, The Hague.

---, http://www.bpbd,jakarta.go.id.,BPBD Provinsi DKI Jakarta, Diakses pada 2017

\section{UCAPAN TERIMAKASIH}

Pada kesempatan ini penulis menyampaikan ucapan terimakasih kepada lembaga penelitian dan pengembangan UHAMKA, FKIP UHAMKA, Tim penelitian dosen pendidikan geografi UHAMKA, dan mahasiswa yang telah mendukung dan menyukseskan dalam terselesaikannya penelitian terkait banjir di DKI Jakarta. Semoga hasil penelitian ini dapat bermanfaat. 